\title{
Loss of AF-6/afadin induces cell invasion, suppresses the formation of glandular structures and might be a predictive marker of resistance to chemotherapy in endometrial cancer
}

\author{
Takuro Yamamoto ${ }^{\dagger}$, Taisuke Mori ${ }^{* \dagger}$, Morio Sawada, Hiroshi Matsushima, Fumitake Ito, Makoto Akiyama \\ and Jo Kitawaki
}

\begin{abstract}
Background: AF-6/afadin plays an important role in the formation of adherence junctions. In breast and colon cancer, loss of AF-6/afadin induces cell migration and cell invasion. We aimed to elucidate the role of AF-6/afadin in human endometrial cancer.

Methods: Morphology and AF-6/afadin expression in endometrial cancer cell lines was investigated by 3-dimensional culture. We used Matrigel invasion assay to demonstrate AF-6/afadin knockdown induced invasive capability. Cell proliferation assay was performed to estimate chemoresistance to doxorubicin, paclitaxel and cisplatin induced by AF-6/afadin knockdown. The associations between AF-6/afadin expression and clinicopathological status were determined by immunohistochemical analysis in endometrial cancer tissues. Informed consent was obtained from all patients before the study.

Results: The majority of cell clumps in 3-dimensional cultures of Ishikawa cells that strongly expressed AF-6/afadin showed round gland-like structures. In contrast, the cell clumps in 3-dimensional cultures of HEC1A and AN3CA cells-both weakly expressing AF-6/afadin-showed irregular gland-like structures and disorganized colonies with no gland-like structures, respectively. AF-6/afadin knockdown resulted in reduced number of gland-like structures in 3-dimensional cultures and enhancement of cell invasion and phosphorylation of ERK1/2 and Src in the highly AF-6/afadin-expressing endometrial cancer cell line. Inhibitors of MAPK/ERK kinase (MEK) (U0126) and Src (SU6656) suppressed the AF-6/afadin knockdown-induced invasive capability. AF-6/afadin knockdown induced chemoresistance to doxorubicin, paclitaxel and cisplatin in Ishikawa cells, not in HEC1A. Immunohistochemical analysis showed that AF-6/afadin expression was significantly associated with myometrial invasion and high histological grade. Conclusions: AF-6/afadin regulates cell morphology and invasiveness. Invasive capability is partly regulated through the ERK and Src pathway. The inhibitors to these pathways might be molecular-targeted drugs which suppress myometrial invasion in endometrial cancer. AF-6/afadin could be a useful selection marker for fertility-sparing therapy for patients with atypical hyperplasia or grade 1 endometrioid adenocarcinoma with no myometrial invasion. AF-6/afadin knockdown induced chemoresistance especially to cisplatin. Therefore, loss of AF-6/afadin might be a predictive marker of chemoresistance to cisplatin.
\end{abstract}

Keywords: AF-6/afadin, Endometrial cancer, Invasion, Morphology, ERK, Src

\footnotetext{
* Correspondence: moriman@koto.kpu-m.ac.jp

${ }^{\dagger}$ Equal contributors

Department of Obstetrics and Gynecology, Kyoto Prefectural University of Medicine, 465 Kajii-cho, Kawaramachi Hirokoji, Kamigyo-ku, Kyoto 602-8566, Japan
}

\section{() Biomed Central}

(C) 2015 Yamamoto et al.; licensee BioMed Central. This is an Open Access article distributed under the terms of the Creative Commons Attribution License (http://creativecommons.org/licenses/by/4.0), which permits unrestricted use, distribution, and reproduction in any medium, provided the original work is properly credited. The Creative Commons Public Domain Dedication waiver (http://creativecommons.org/publicdomain/zero/1.0/) applies to the data made available in this article, unless otherwise stated. 


\section{Background}

Endometrial cancer is one of the most common gynecological malignancies and its incidence has increased remarkably [1,2]. Endometrial cancers are broadly classified into two groups: (1) Type 1 disease, the most common type of endometrial cancer, is estrogen-related, low-grade, histologically endometrioid adenocarcinoma in most cases and shows minimal myometrial invasion and occurs at a younger age. (2) Type 2 disease is high-grade, histologically serous or clear cell adenocarcinoma and shows deep myometrial invasion [3].

Cell polarity and cell-cell adhesion are essential for normal functioning of epithelial tissues. In cancer, the epithelial-mesenchymal transition (EMT) is a process where epithelial cells detach from primary tumors, invade into the surrounding tissues, metastasize, and grow at a secondary site [4]. Cell-cell junctions are lost in EMT. Most patients present with low-grade and earlystage endometrial cancer. However, once the disease spreads beyond the uterus, the prognosis is poor, and the 5-year survival is $25-45 \%$ for stage III and IV [5]. Therefore, it is essential to decrease tumor invasiveness for the treatment of endometrial cancer.

AF-6/afadin is encoded by the MLLT4 gene located on chromosome 6, band q27 [6]. AF-6/afadin binds to nectins, plays important cooperative roles in the formation of adherens junctions, and is associated with the actin cytoskeleton [7]. It is also important for cell polarity at cell-cell junctions $[8,9]$. Conversely, AF-6/afadin at the leading edge does not bind nectins, and enhances cell movement [10]. Thus, AF-6/afadin has conflicting role in cell invasion. AF-6/afadin loss induces cell migration, invasion, and proliferation, and is a prognostic indicator in breast and colon cancer [11-14]. However, its role and expression in endometrial cancer have not been studied. In this study, we investigate for the first time the expression of AF-6/afadin in patients with endometrial cancer and its role in cell invasion and chemoresistance in endometrial cancer.

\section{Methods}

\section{Cell lines and materials}

The Ishikawa line of human uterine endometrial cancer cells was provided by the Cell Resource Center for Biomedical Research (Institute of Development, Aging and Cancer, Tohoku University, Japan). The HEC1A and AN3CA cells were purchased from the American Type Culture Collection. The Ishikawa and AN3CA cells were maintained in Eagle's MEM (Nacalai Tesque, Kyoto, Japan) with nonessential amino acids, sodium pyruvate, and $10 \%$ fetal bovine serum (FBS) (Invitrogen Corp., Carlsbad, CA). The HEC1A cells were maintained in McCoy's 5A (HyClone, Logan, UT) with sodium pyruvate, supplemented with $10 \%$ FBS. We focused on endometrioid adenocarcinoma because it was the major type observed, and the histological grade and myometrial invasion are important for its diagnosis and treatment. All patient samples used for this study were obtained from University hospital, Kyoto Prefectural University. The Kyoto Prefectural University of Medicine human research ethics board approved all protocols and patients gave informed consent.

\section{RNA isolation and quantitative PCR analysis}

Total RNA $(1 \mu \mathrm{g})$ was isolated from the cells, 24 or $48 \mathrm{~h}$ after siRNA transfection, using the RNeasy mini kit (Qiagen, Hilden, Germany) according to the manufacturer's instructions. Each cDNA was synthesized from $1 \mu \mathrm{g}$ RNA using the ReverTra Ace qPCR RT kit (Toyobo, Osaka, Japan). Real-time reverse transcriptionPCR was carried out using the CFX Connect ${ }^{\mathrm{TM}}$ Real-Time System (Bio-Rad, Hercules, CA). cDNA samples prepared from the total RNA of Ishikawa, HEC1A, and AN3CA cells $(1 \mu \mathrm{L})$ were mixed in $20-\mu \mathrm{L}$ reactions containing SYBR qPCR Thunderbird master mix (Toyobo, Osaka, Japan) and $0.2 \mu \mathrm{mol} / \mathrm{L}$ of each primer. Primers, AF-6/afadin 5'-GTGGGACAGCATTACCGA CA-3' (forward) and 5' -TCATCGGCTTCACCATTCC3' (reverse) and Glyceraldehyde 3-phosphate dehydrogenase (GAPDH) 5'-GCACCGTCAAGGCTGAGAAC-3' (forward) and 5'-ATGGTGGTGAAGACGCCAGT-3' (reverse) were designed with Primer 3 software. The amplification, detection, and data analysis were performed using the CFX Connect ${ }^{\mathrm{Tm}}$ Real-Time System. Each sample was analyzed in triplicate. The expression levels of genes were determined relative to the expression level of GAPDH.

\section{RNA interference}

Small interfering RNAs (siRNA) for MLLT4/AF-6 (s8829, s8830 and s8831) and a negative control siRNA (control \#1) targeting no known genes were Silencer ${ }^{\odot}$ Select siRNAs purchased from Ambion (Austin, TX). Cells were transfected with the siRNA using Lipofectamine RNAiMAX (Invitrogen, Carlsbad, CA) according to the manufacturer's instructions, and used for each experiment after 24 or $48 \mathrm{~h}$. AF-6/afadin KD effects were measured with real-time PCR and western blotting. We decided to use siRNA for AF-6/afadin (s8830) for the following experiments, because it has the strongest KD activity of the validated siRNAs.

\section{Three-dimensional cell culture}

Cells $\left(2.5 \times 10^{5}\right)$ from the Ishikawa, HEC1A, and AN3CA lines were trypsinized and suspended in $800 \mu \mathrm{L}$ of $\mathrm{BD}$ Matrigel $^{\mathrm{TM}}$ Matrix Basement Membrane (BD biosciences, Bedford, MA), as previously described [15]. The paraffinembedded specimens were cut into $3.5-\mu \mathrm{m}$ sections for 
hematoxylin-eosin staining and AF-6/afadin immunohistochemical staining. Each experiment was performed three times.

\section{Matrigel invasion assay}

Cells $\left(2.0 \times 10^{5}\right)$ were seeded into the top of a Matrigel invasion chamber (24-well insert; pore size, $8 \mu \mathrm{m}$; BD Biosciences, Bedford, MA) containing a serum-free and a medium with $10 \%$ FBS was used as a chemoattractant in the lower chamber. The cells were incubated for $48 \mathrm{~h}$ at $37^{\circ} \mathrm{C}$. A cotton swab was used to remove the cells, that did not invade through the pore and cells that had migrated to the lower surface of the membrane were stained with the Diff-Quik kit (Sysmex, Kobe, Japan) and counted.

\section{Cell proliferation assay}

Cells $\left(5.0 \times 10^{3}\right)$ were seeded into 96-well plates containing a normal growth medium, and RNA interference was performed after $24 \mathrm{~h}$. The anticancer drugs were added at various doses, $24 \mathrm{~h}$ after siRNA transfection. The cells were cultured and treated in quadruplicate, and cell viability was examined after $72 \mathrm{~h}$ by the 2-(2methoxy-4-nitrophenyl)-3-(4-nitrophenyl)-5-(2,4-disulphonyl)-2H-tetrazolium (WST-8) assay (Nacalai Tesque, Kyoto, Japan).

\section{Antibodies}

A mouse anti-AF-6/afadin antibody (clone 35) was purchased from Becton Dickinson. A mouse anti-Src antibody (\# 2110) and rabbit anti-GAPDH (\# 2118), anti-ERK1/2 (\# 9102), anti-phospho-ERK1/2 (Thr202/ Tyr204), and anti-phospho-Src family (Tyr416) (\# 2101) antibodies were purchased from Cell Signaling Technology (Beverly, MA). All antibodies were used at the concentration recommended by the manufacturers.

\section{Western blotting}

Cells were washed twice in phosphate-buffered saline and lysed in RIPA buffer (Nacalai Tesque, Kyoto, Japan).

Cell lysates $(20 \mu \mathrm{g})$ were heated in sodium dodecyl sulfate (SDS) sample buffer (125 mM Tris-HCl, pH 6.8, 4\% SDS, 25\% glycerol, 10\% 2-mercaptoethanol, $0.05 \mathrm{mM}$ phenylmethanesulfonyl fluoride and $0.004 \%$ bromophenol blue), separated using 10\% e-PAGEL according to the manufacturer's recommendations (Atto Corp, Tokyo, Japan), and transferred onto Immuno-Blot ${ }^{\circ}$ PVDF membranes (Bio-Rad, Hercules, CA). The membranes were blocked in Tris-buffered saline supplemented with 5\% fat-free milk for $1 \mathrm{~h}$ and then incubated with indicated antibodies at $4^{\circ} \mathrm{C}$ overnight. After washing, the membranes were incubated with the secondary antibody for $1 \mathrm{~h}$ at room temperature. The signal was developed using Chemi-Lumi One Super (Nacalai Tesque, Kyoto,
Japan) and analyzed by a ChemiDoc XRS system with Image Lab software (Bio-Rad, Hercules, CA).

\section{Immunohistochemistry}

Specimens from patients who underwent abdominal hysterectomy because of uterine endometrial cancer were used for this study. Informed consent was obtained from all the patients before the study was conducted. The protocol has been previously described [16]. The AF-6/ afadin immunoreactivities were scored using a semiquantitative index, the $\mathrm{H}$-score. The $\mathrm{H}$-score is the product of the intensity of staining (given a value of 0,1 , 2 , or 3 for negative, weak, moderate, or strong, respectively) and the percentage of stained epithelial cells at each intensity $(0-100 \%)$. Samples with H-score $\geq 50$ were deemed as AF-6/afadin-positive.

\section{Statistical analysis}

Progression-free survival and overall survival were assessed using the Kaplan-Meier method and log-rank

\begin{tabular}{|c|c|c|c|}
\hline \multicolumn{4}{|l|}{ AF-6/afadin immunoreactivity } \\
\hline Uterine endometrial cancer & $\begin{array}{l}\text { Positive } \\
(n=51)\end{array}$ & $\begin{array}{l}\text { Negative } \\
(n=39)\end{array}$ & $P$ value \\
\hline Mean age (range) & $55.9(32-83)$ & $58.6(28-80)$ & 0.41 \\
\hline \multicolumn{4}{|l|}{ Histological type } \\
\hline Endometrioid & $51(100 \%)$ & $34(87.2 \%)$ & \\
\hline Serous & 0 & $3(7.7 \%)$ & \\
\hline Clear & 0 & $2(5.1 \%)$ & 0.21 \\
\hline Endometrioid adenocarcinoma & $\begin{array}{l}\text { Positive } \\
(n=51)\end{array}$ & $\begin{array}{l}\text { Negative } \\
(n=34)\end{array}$ & $P$ value \\
\hline \multicolumn{4}{|l|}{ Histological grade } \\
\hline 1 & $38(74.5 \%)$ & $11(32.4 \%)$ & \\
\hline 2 & $11(21.6 \%)$ & $13(38.2 \%)$ & \\
\hline 3 & $2(3.9 \%)$ & $10(29.4 \%)$ & $P<0.01$ \\
\hline \multicolumn{4}{|l|}{ Myometrial invasion } \\
\hline No invasion & $14(27.5 \%)$ & $1(2.9 \%)$ & \\
\hline Less than half & $26(51.0 \%)$ & $15(44.1 \%)$ & \\
\hline More than half & $11(21.6 \%)$ & $18(52.9 \%)$ & $P<0.01$ \\
\hline \multicolumn{4}{|l|}{ Lymph node metastasis } \\
\hline Negative & $48(94.1 \%)$ & $30(88.2 \%)$ & \\
\hline Positive & $3(5.9 \%)$ & $4(11.8 \%)$ & 0.57 \\
\hline \multicolumn{4}{|l|}{ Stage } \\
\hline I & $37(72.5 \%)$ & $25(73.5 \%)$ & \\
\hline$\|$ & $7(13.7 .8 \%)$ & $2(5.9 \%)$ & \\
\hline III & $6(11.8 \%)$ & $6(17.6 \%)$ & \\
\hline IV & $1(2.0 \%)$ & $1(2.9 \%)$ & 0.82 \\
\hline
\end{tabular}

Cases with $\mathrm{H}$-score $>50$ are positive. 
test. Comparisons of the means and standard error of data between two groups were performed using the Student's $t$ test. Comparisons of over 3 groups were performed using the Kruskal-Wallis H-test, and the MannWhitney U-test with Bonfferoni correction was as a post hoc test. Statistical differences between AF-6/afadin status and histological type, histological grade, myometrial invasion, lymph node status, and stage were evaluated using a chi-square test. $\mathrm{P}$ values $<0.05$ were considered significant.

\section{Results}

Low expression levels of AF-6/afadin in uterine endometrial cancer tissues were associated with myometrial invasion and high histological grade

All sections of normal endometrium stained positive for AF-6/afadin. AF-6/afadin was expressed in the cytoplasm and at the surface of the epithelial cells. The association between AF-6/afadin immunoreactivity and clinicopathological status are shown in Table 1. Of the 90 endometrial cancer cases, 85 cases were endometrioid adenocarcinomas.

The H-score of AF-6/afadin was significantly associated with histological grade (between grade 1 and 2 cases, and between grade 1 and 3 cases, $P<0.01$ ) and myometrial invasion (between cases with no invasion and cases with a myometrial invasion depth of more than 50\%, $P<0.01$ ) in endometrioid adenocarcinoma (Figure 1b, c). The H-score of the normal endometrium ( $\mathrm{n}=10$ ) was significantly higher than that of the endometrioid adenocarcinoma (between normal endometrium and grade $1, P<0.05$, and between normal endometrium and grade 2 , and $3, P<0.01$ ) (Figure $1 \mathrm{~b}$ ). However, there were no significant associations between the AF-6/afadin immunoreactivity and the FIGO stage, lymph node metastasis, progression-free survival (PFS),

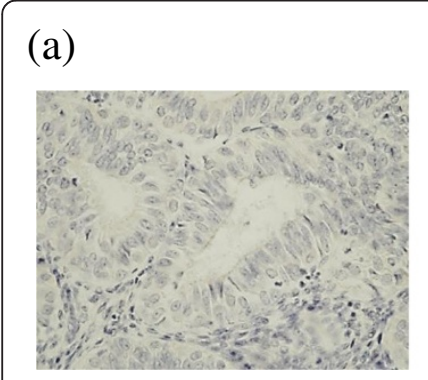

Negative: 0

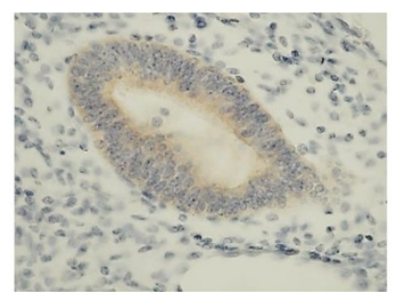

Weak positive: 1

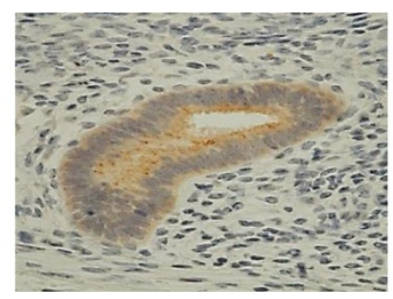

Moderate positive: 2

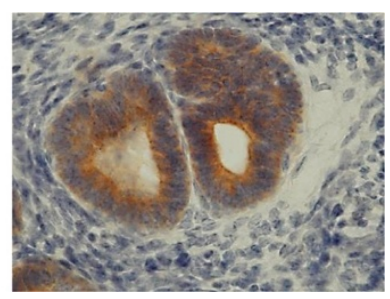

Strong positive : 3 (b)

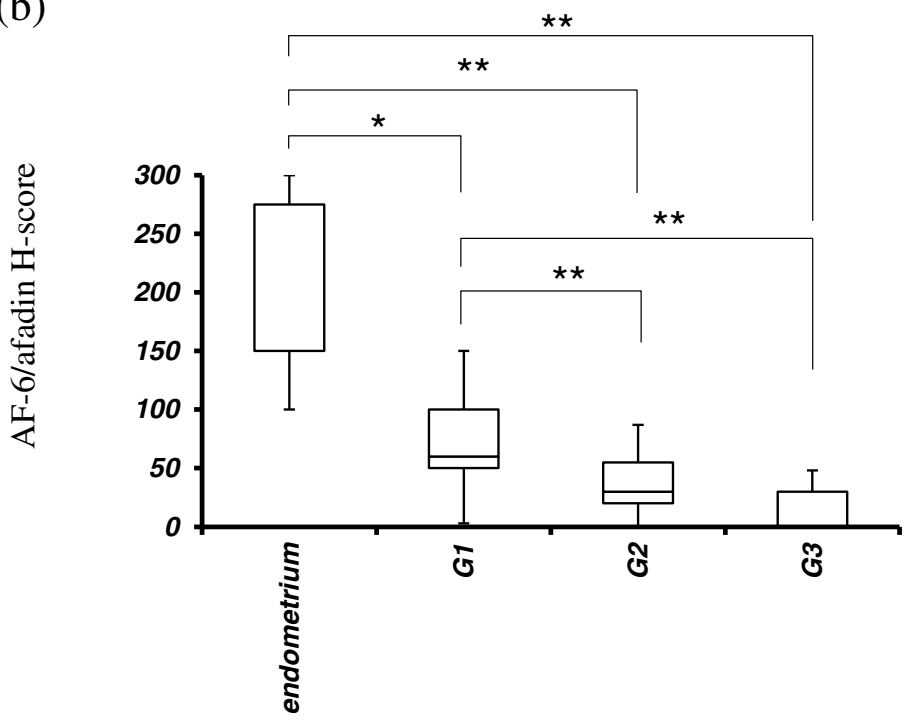

(c)

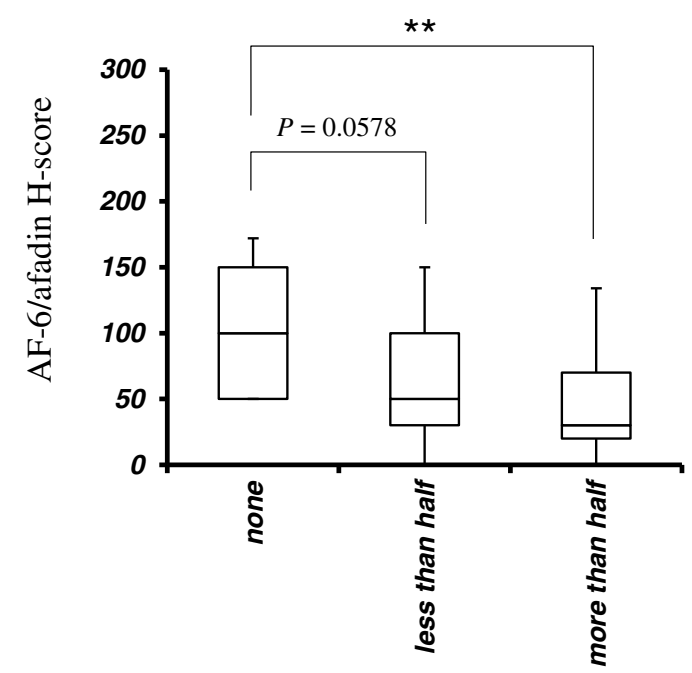

Figure 1 Association of AF-6/afadin expression with histological grade and myometrial invasion in 85 endometrioid adenocarcinomas. (a) The staining values of $0,1,2$, or 3 are negative, weak, moderate, or strong, respectively. (b, c) Low H-score of AF-6/afadin immunoreactivity was associated with high histological grade (between grade 1 and 2 cases, and between grade 1 and 3 cases, $P<0.01$, and 0.01 , respectively) and deep myometrial invasion (between no invasion and more than half invasion cases, $P<0.01)(\mathbf{b})$. The correlations between AF-6/afadin $\mathrm{H}$-score and histological grade or myometrial invasion were assessed with the Kruskal-Wallis H-test; the Mann-Whitney U-test with Bonfferoni correction was used as a post hoc test. Significant differences were indicated as * for $P<0.05$ and ** for $P<0.01$. 
or overall survival (OS) $(P=0.18$ and 0.21 for PFS and OS, respectively).

\section{AF-6/afadin plays an important role in 3-dimensional cultures of Ishikawa, HEC1A, and AN3CA cells}

To investigate AF-6/afadin expression and morphology, 3-dimensional (3D) culture was performed. AF-6/afadin mRNA level in 3D cultures was significantly higher than that in monolayer cultures in Ishikawa cells $(P<0.01)$, similar to that in monolayer cultures in the HEC1A, and significantly lower than that in monolayer cultures in AN3CA cells $(P<0.01)$ (Figure $2 \mathrm{a})$. AF-6/afadin immunostaining was strongly, weakly, and very weakly positive in the Ishikawa, HEC1A, and AN3CA cells, respectively. The majority of the cell clumps in 3D cultures of Ishikawa cells showed round gland-like structures, whereas the cell clumps in 3D cultures of HEC1A and AN3CA showed irregular gland-like structures and disorganized colonies with no gland-like structures, respectively (Figure 2b). RNA interference experiments to knockdown (KD) AF-6/afadin and subsequent 3D cultures were performed using the Ishikawa cells. In this assay, paraffin specimens were prepared on day 5 when the
AF-6/afadin KD was still maintained. AF-6/afadin KD increased the number of disorganized colonies and reduced the number of gland-like structures in 3D cultures of Ishikawa cells $(P<0.01)$ (Figure 3$)$.

\section{AF-6/afadin KD induced phosphorylation of ERK1/2 and Src kinase and stimulated cell invasion in AF-6/afadin-positive cell lines}

First, we evaluated whether AF-6/afadin regulates cell migration and invasion in endometrial cancer, using trans-well cell culture inserts and the Matrigel Invasion chamber system. We used Ishikawa (AF-6/afadin strong positive) cells and HEC1A (AF-6/afadin weak positive) cells. AF-6/afadin KD cells significantly enhanced the invasive capability in the Ishikawa and HEC1A compared with negative control cells $(P<0.05)$ (Figure $4 \mathrm{a}-\mathrm{d})$; however, although the migratory capability was examined using Trans-well cell culture inserts without Matrigel coating, it remained unchanged (data not shown).

We next investigated how AF-6/afadin KD stimulates invasive capability. In Ishikawa cells, AF-6/afadin KD induced phosphorylation of ERK1/2 and Src kinases. Conversely, in HEC1A cells, ERK1/2 and Src kinase were

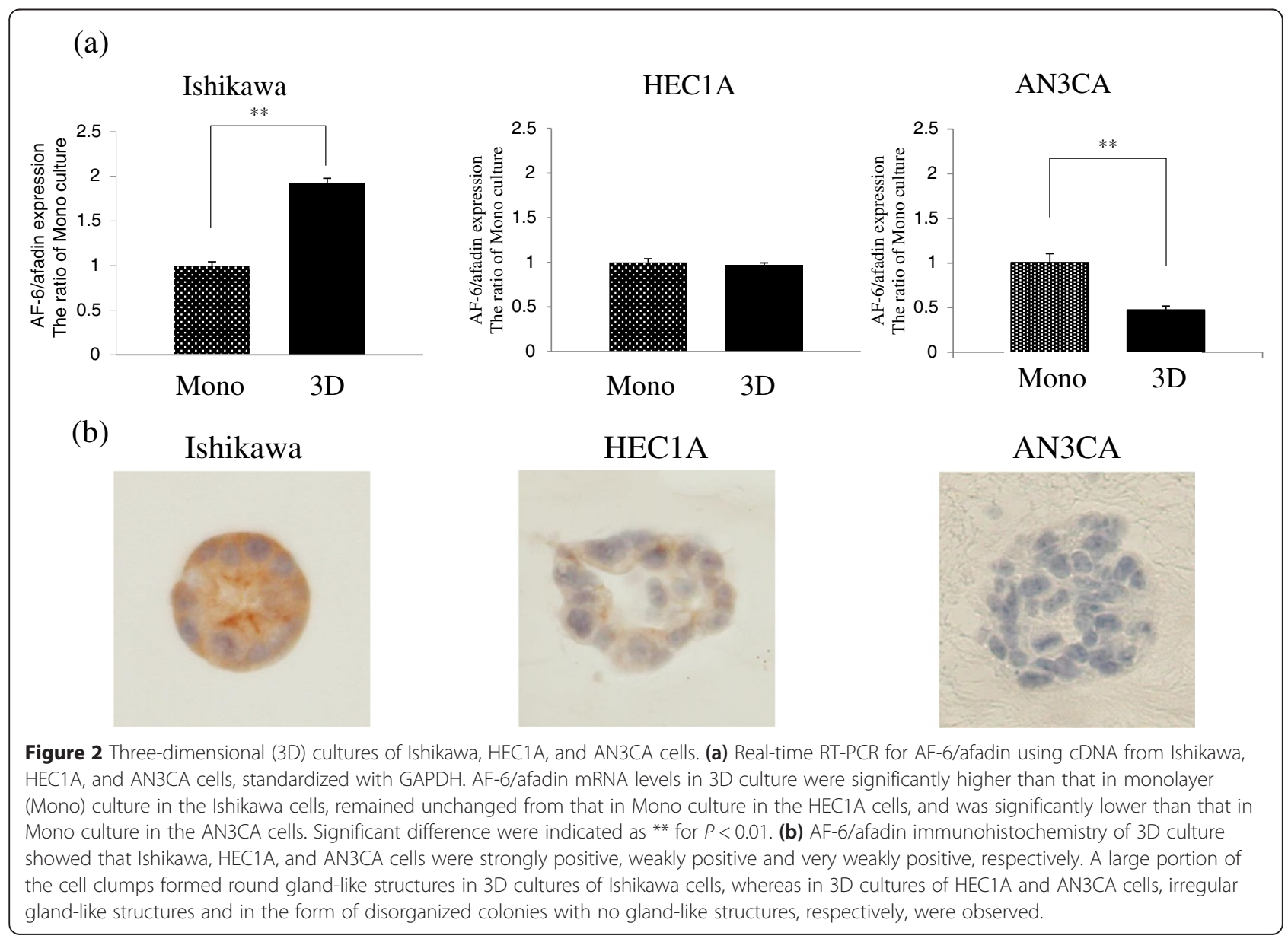




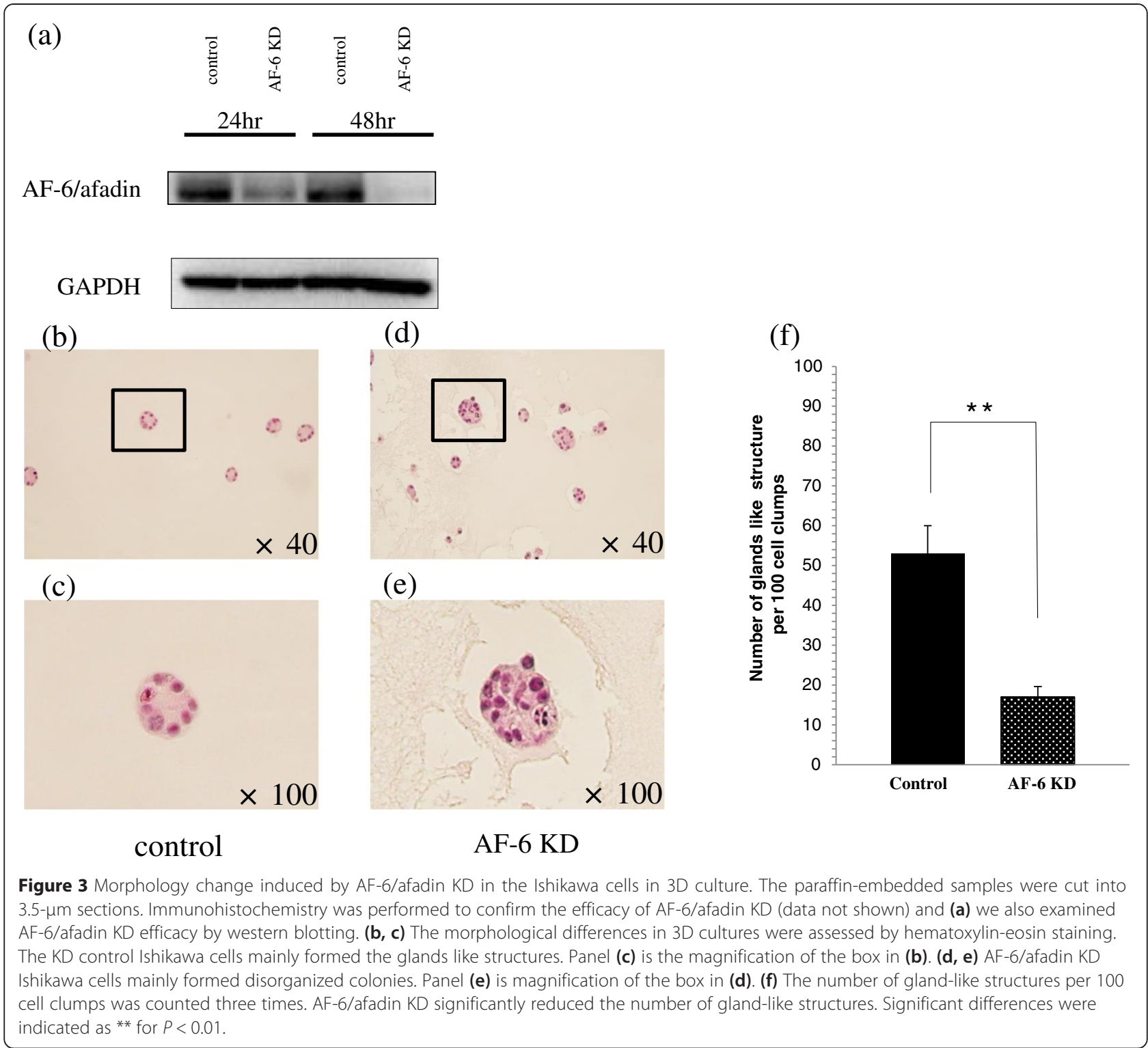

already activated and AF-6/afadin KD did not significantly increase the level of phosphorylated ERK1/2 or Src (Figure 4e). This result indicates that AF-6/afadin functions as a suppressor of ERK and Src phosphorylation pathways. Using the MEK inhibitor (U0126) and the Src kinase inhibitor (SU6656), we demonstrated the importance of ERK1/2 and Src phosphorylation for regulating the cell invasion induced in the Ishikawa cells by AF-6/afadin KD. First, we determined the concentrations of U0126 and SU6656 (5 $\mu \mathrm{M}$ and $1 \mu \mathrm{M}$, respectively). At the determined concentrations, the reagents inhibited phosphorylation of ERK1/2 and Src, and did not influence the proliferation of the Ishikawa cells (data not shown). At these concentrations, U0126 and SU6656 significantly inhibited Ishikawa cell invasions induced by
AF-6/afadin KD (Figure 5). This result indicates that AF-6/afadin KD induced cell invasion through ERK and Src signaling pathways.

\section{AF-6/afadin KD induced chemoresistance to doxorubicin, paclitaxel and cisplatin in AF-6/afadin strongly positive cell line}

To estimate chemoresistance to doxorubicin, paclitaxel and cisplatin induced by AF-6/afadin KD, we performed the WST-8 assay cell proliferation assay using. In Ishikawa cells, AF-6/afadin KD induced slight chemoresistance to doxorubicin and paclitaxel, and strong resistance to cisplatin (Figure 6a-c, respectively). However, AF-6/afadin did not induce chemoresistance in HEC1A cells (Figure 6d-e). 


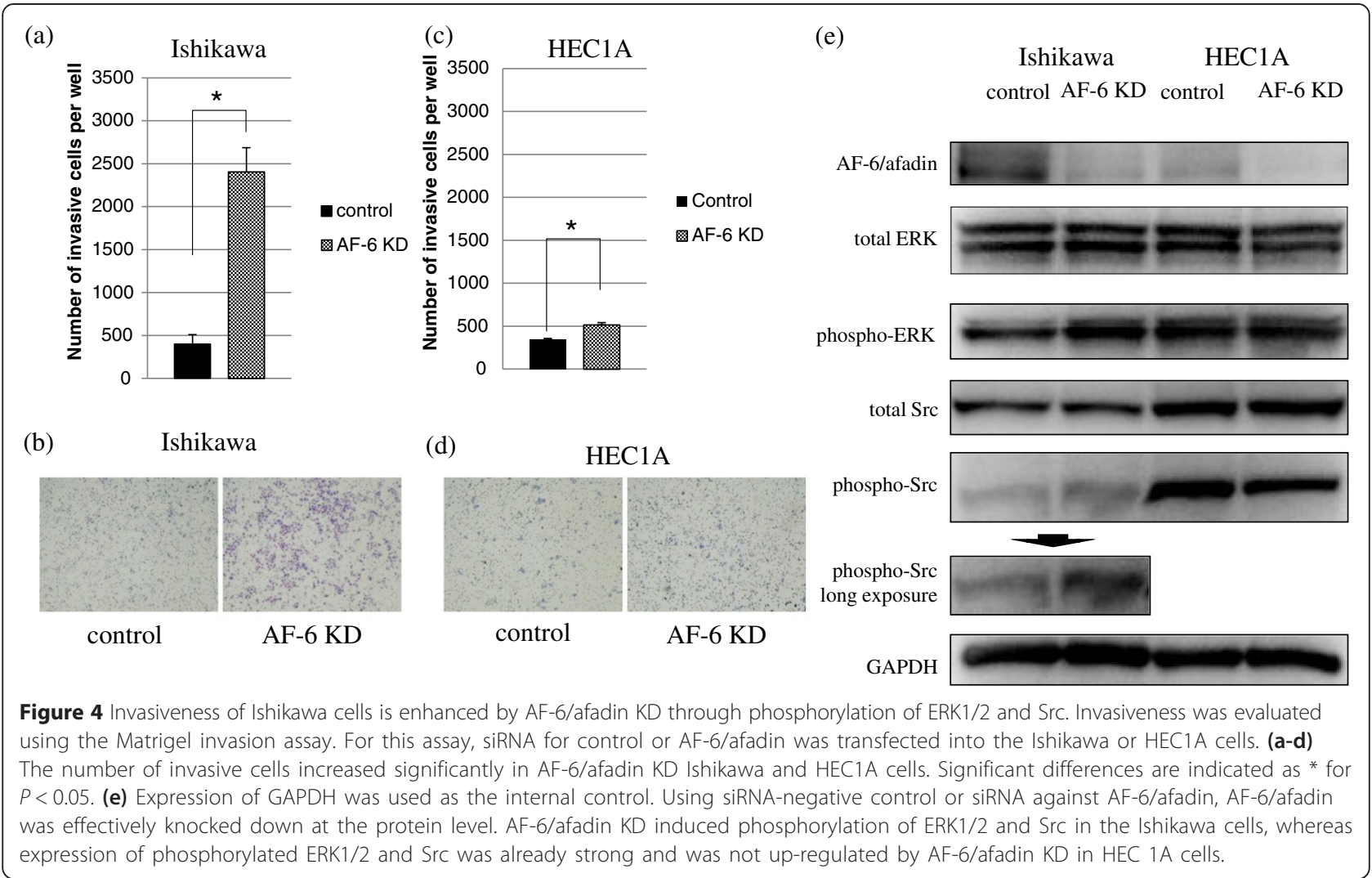

\section{Discussion}

AF-6/afadin is expressed in almost all normal epithelial tissues where it is involved in forming the actin cytoskeleton by binding actin filaments and nectins (immunoglobulin-like cell adhesion molecules) [17]. AF-6/afadin, in cooperation with nectins, involved in the formation of a variety E-cadherin-dependent or E-cadherin-independent cell-cell junctions $[7,9,18,19]$. Decreased E-cadherin expression is associated with poor prognosis, high histological grade and advanced stage in endometrial cancer [20-22]. Immunohistochemical analysis revealed that AF-6/afadin expression in endometrial cancer tissues was lower than that in normal endometrial tissues. Furthermore, loss of AF-6/afadin expression was associated with myometrial invasion and high histological grade in patients with endometrial cancer.

Three-dimensional cell culture is a useful model to investigate molecular signaling and cellular behavior during epithelial morphogenesis [23]. In this study, when comparing the mRNA levels in monolayer and 3D cultures, the mRNA levels of nectins in both cultures were found to be similar, while AF-6/afadin mRNA levels in well-differentiated and poorly differentiated endometrial cancer cell lines were higher and lower, respectively, in the $3 \mathrm{D}$ cultures. These results suggest that AF-6/afadin could be an important scaffold protein determining epithelial morphogenesis in uterine endometrial cancer.

AF-6/afadin was strongly expressed in Ishikawa cells, a well-differentiated and grade 1 equivalent endometrial adenocarcinoma cell line, whereas AF6/afadin was weakly expressed in HEC1A and AN3CA cells, which are derived from grade 2 and grade 3 endometrial adenocarcinomas, respectively. In 3D cultures, AF-6/ afadin expression was positively associated with the formation of round gland-like structures. AF-6/afadin was expressed in all normal endometrial tissues and most well-differentiated endometrial adenocarcinomas in our study. Therefore, we investigated the function of AF-6/afadin using an RNA interference assay. In endometrioid cancers, histological grade is defined in terms of solid tumor growth; increased solid growth is associated with high histological grade and a high degree of cellular atypia [24]. AF-6/afadin KD resulted in fewer gland-like structures and more disorganized colonies in Ishikawa cell cultures than in the KD control cultures. This result explains why AF-6/ afadin loss was associated with higher histological grade. AF-6/afadin KD significantly enhanced cell invasion in AF-6/afadin-positive endometrial cancer cell lines. These results suggest that AF-6/afadin serves 


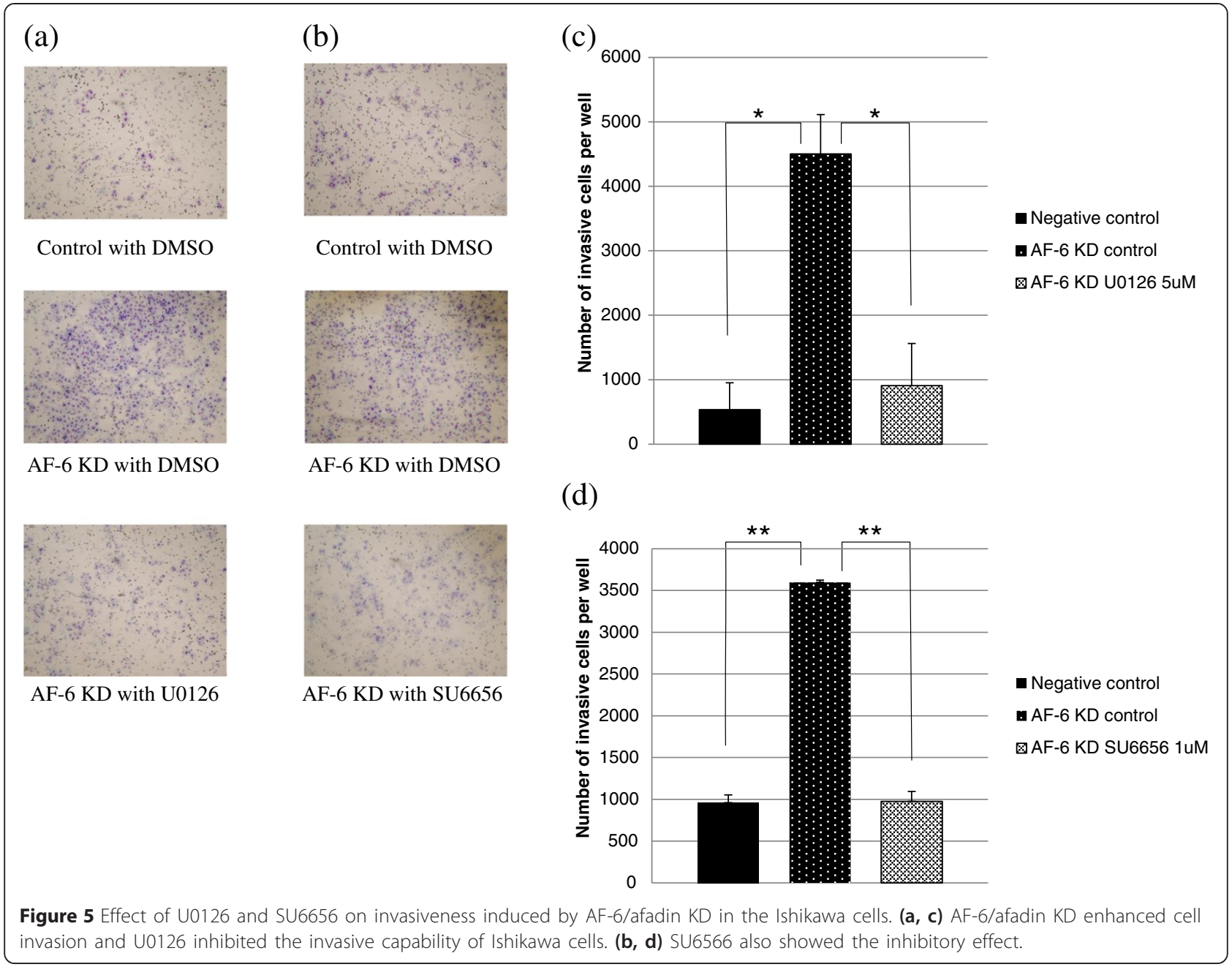

as a positive regulator of duct formation and as an inhibitor of tissue invasion in human endometrial cancer.

We focused on the cell signaling pathways induced by AF-6/afadin KD to determine the mechanisms underlying these findings. A Src signaling is important in multiple physiological homeostatic pathways that regulate cell proliferation, cell survival, cytoskeleton regulation, intracellular contacts, cell-matrix adhesion, motility, and migration [25,26]. An Src mutation at codon 537 was previously detected in a small subset of endometrial cancers [27]. In this study, we demonstrated that enhancement of phosphorylation in the Src kinase family was induced by AF-6/afadin KD in the strongly AF-6/afadinpositive Ishikawa cells. The AF-6/afadin KD-induced invasiveness of the Ishikawa cells was repressed by SU6656, an Src inhibitor. These findings indicate that AF-6/afadin might regulate cell invasion through the Src signaling pathway.

RAS/RAF/MEK/ERK pathways are also important for cell proliferation and survival in several cancers [28-33].
AF-6/afadin links to Bcr and RAS and down-regulates RAS-dependent stimulation of the RAF/MEK/ERK signaling pathway [34]. The activation of ERK1/2 induced by AF-6/afadin KD has been reported in breast cancer [12]. We also found that AF-6/afadin KD increased phosphorylation of ERK1/2 proteins. In addition, U0126, a MEK inhibitor, also suppressed AF-6/afadin KD induced phosphorylation of ERK1/2 and cell invasion in endometrial cancer. These results also suggest that AF6/afadin KD induced cell invasion through the RAF/ MEK/ERK signaling pathway.

Chemoresistance is an important problem in cancer therapy. The ERK pathway has been implicated in chemoresistance to doxorubicin, paclitaxel and cisplatin in some cancers [35-39], although the findings are controversial. AF-6/afadin KD increased the phosphorylation of ERK $1 / 2$ in Ishikawa cells, but not in HEC1A cells. AF-6/afadin KD also induced chemoresistance to doxorubicin, paclitaxel, and cisplatin in AF-6/afadin strongly positive Ishikawa cells. These results suggest that the 


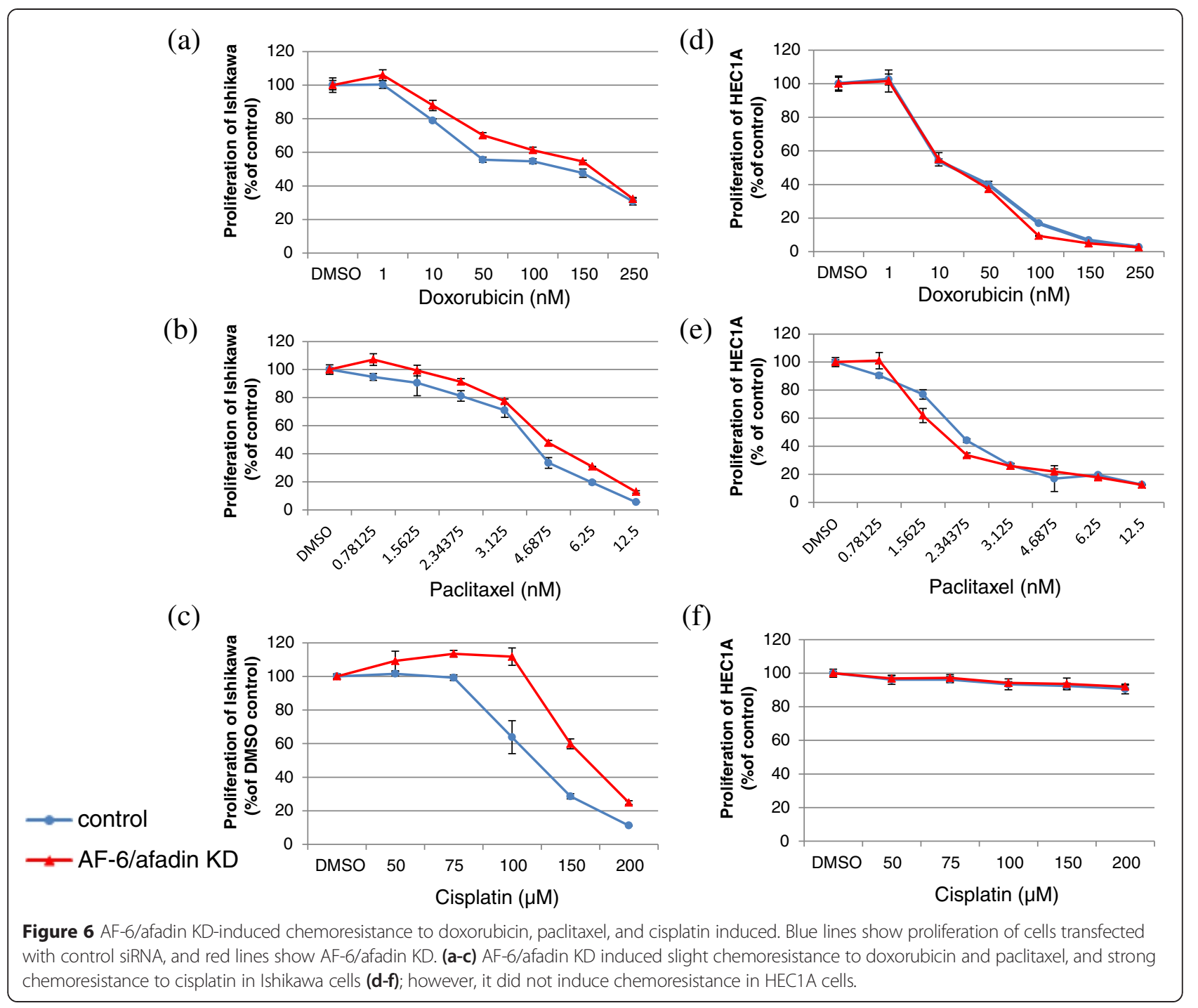

ERK pathway could be involved in the chemoresistance induced by AF-6/afadin KD.

\section{Conclusions}

In this study, we demonstrated that AF-6/afadin regulates cell invasion through ERK and Src pathway. The inhibitors to these pathways might be moleculartargeted drugs which suppress myometrial invasion in endometrial cancer. AF-6/afadin is an important scaffold protein and might be crucial for maintenance of the ductal structure of glands in the endometrium. Reduced expression of AF-6/afadin is associated with high histological grade and myometrial invasion of endometrial cancers. AF-6/afadin could be a useful selection marker for fertility-sparing therapy for the patients with atypical hyperplasia or grade 1 endometrioid adenocarcinoma with no myometrial invasion. AF-6/afadin KD induced strong chemoresistance to cisplatin. Therefore, loss of
AF-6/afadin might be a predictive marker of chemoresistance to cisplatin.

\section{Abbreviations}

3D: Three-dimensional; EMT: Epithelial-mesenchymal transition; KD: Knockdown; PFS: Progression-free survival; OS: Overall survival; FBS: Fetal bovine serum; siRNA: Short interfering RNA.

\section{Competing interests}

The authors declare that they have no competing interests.

\section{Authors' contributions}

TY conceived the study, carried out all the experiments and drafted the manuscript. TM conceived the study, participated in the design of the study, helped to draft the manuscript and acted as a corresponding author. MS carried out the immunohistochemical analysis. HM participated in the design of the study and carried out the invasion assay. FI participated in the design of the study and performed the statistical analysis. MA participated in the design of the study and carried out immunohistochemical analysis. JK supervised research projects and revised the manuscript. All authors read and approved the final manuscript. 


\section{Acknowledgement}

This study was supported by Grant-in-Aid for scientific research (no.23791849) from the Ministry of Education, Culture, Sports, Science, and Technology, Japan.

\section{Received: 25 December 2014 Accepted: 30 March 2015} Published online: 12 April 2015

\section{References}

1. Aoki D. Annual report of gynecologic oncology committee, Japan society of obstetrics and gynecology, 2013. J Obstet Gynaecol Res. 2014;40(2):338-48.

2. Ushijima K. Current status of gynecologic cancer in Japan. J Gynecol Oncol. 2009;20(2):67-71.

3. Sorosky J. Endometrial cancer. Obstet Gynecol. 2008;111(2 Pt 1):436-47.

4. Yilmaz M, Christofori G. EMT, the cytoskeleton, and cancer cell invasion. Cancer Metastasis Rev. 2009;28(1-2):15-33.

5. Amant F, Moerman P, Neven P, Timmerman D, Van Limbergen E, Vergote I. Endometrial cancer. Lancet. 2005;366(9484):491-505.

6. Saha V, Lillington DM, Shelling AN, Chaplin T, Yaspo ML, Ganesan TS, et al. AF6 gene on chromosome band 6q27 maps distal to the minimal region of deletion in epithelial ovarian cancer. Genes Chromosomes Cancer. 1995;14(3):220-2.

7. Takahashi K, Nakanishi H, Miyahara M, Mandai K, Satoh K, Satoh A, et al. Nectin/PRR: an immunoglobulin-like cell adhesion molecule recruited to cadherin-based adherens junctions through interaction with Afadin, a PDZ domain-containing protein. J Cell Biol. 1999;145(3):539-49.

8. Asakura T, Nakanishi H, Sakisaka T, Takahashi K, Mandai K, Nishimura M, et al. Similar and differential behaviour between the nectin-afadin-ponsin and cadherin-catenin systems during the formation and disruption of the polarized junctional alignment in epithelial cells. Genes Cells. 1999;4(10):573-81.

9. Takai $Y$, Nakanishi H. Nectin and afadin: novel organizers of intercellular junctions. J Cell Sci. 2003;116(Pt 1):17-27.

10. Miyata M, Ogita H, Komura H, Nakata S, Okamoto R, Ozaki M, et al. Localization of nectin-free afadin at the leading edge and its involvement in directional cell movement induced by platelet-derived growth factor. J Cell Sci. 2009;122(Pt 23):4319-29.

11. Elloul S, Kedrin D, Knoblauch NW, Beck AH, Toker A. The Adherens Junction Protein Afadin Is an AKT Substrate that Regulates Breast Cancer Cell Migration. Mol Cancer Res. 2014.

12. Fournier $\mathrm{G}$, Cabaud $\mathrm{O}$, Josselin $\mathrm{E}_{1}$ Chaix $\mathrm{A}$, Adelaide J, Isnardon $\mathrm{D}$, et al. Loss of AF6/afadin, a marker of poor outcome in breast cancer, induces cell migration, invasiveness and tumor growth. Oncogene. 2011;30(36):3862-74.

13. Sun $T$, Wang $Y$, Cheng H, Zhang XH, Xiang JJ, Zhang JT, et al. Disrupted interaction between CFTR and AF-6/afadin aggravates malignant phenotypes of colon cancer. Biochim Biophys Acta. 2013;1843(3):618-28.

14. Letessier A, Garrido-Urbani S, Ginestier C, Fournier G, Esterni B, Monville F, et al. Correlated break at PARK2/FRA6E and loss of AF-6/Afadin protein expression are associated with poor outcome in breast cancer. Oncogene. 2007;26(2):298-307.

15. Koshiba H, Hosokawa K, Kubo A, Tokumitsu N, Watanabe A, Honjo H. Junctional adhesion molecule A [corrected] expression in human endometrial carcinoma. Int J Gynecol Cancer. 2009;19(2):208-13.

16. Yamamoto T, Mori T, Sawada M, Kuroboshi H, Tatsumi H, Yoshioka T, et al. Estrogen-related receptor-gamma regulates estrogen receptor-alpha responsiveness in uterine endometrial cancer. Int J Gynecol Cancer. 2012;22(9):1509-16.

17. Mandai K, Nakanishi $H$, Satoh A, Obaishi H, Wada M, Nishioka $H$, et al. Afadin: A novel actin filament-binding protein with one PDZ domain localized at cadherin-based cell-to-cell adherens junction. J Cell Biol. 1997; 139(2):517-28

18. Ooshio T, Irie K, Morimoto K, Fukuhara A, Imai T, Takai Y. Involvement of LMO7 in the association of two cell-cell adhesion molecules, nectin and E-cadherin, through afadin and alpha-actinin in epithelial cells. J Biol Chem. 2004;279(30):31365-73

19. Sato T, Fujita N, Yamada A, Ooshio T, Okamoto R, Irie $K$, et al. Regulation of the assembly and adhesion activity of E-cadherin by nectin and afadin for the formation of adherens junctions in Madin-Darby canine kidney cells. J Biol Chem. 2006;281(8):5288-99.

20. Mell LK, Meyer JJ, Tretiakova M, Khramtsov A, Gong C, Yamada SD, et al. Prognostic significance of E-cadherin protein expression in pathological stage I-III endometrial cancer. Clin Cancer Res. 2004;10(16):5546-53.
21. Moreno-Bueno G, Hardisson D, Sarrio D, Sanchez C, Cassia R, Prat J, et al. Abnormalities of E- and P-cadherin and catenin (beta-, gamma-catenin, and p120ctn) expression in endometrial cancer and endometrial atypical hyperplasia. J Pathol. 2003;199(4):471-8.

22. Gonzalez-Rodilla I, Aller L, Llorca J, Munoz AB, Verna V. The E-Cadherin expression vs. tumor cell proliferation paradox in endometrial cancer. Anticancer Res. 2013;33(11):5091-5.

23. O'Brien LE, Zegers MM, Mostov KE. Opinion: Building epithelial architecture: insights from three-dimensional culture models. Nat Rev Mol Cell Biol. 2002;3(7):531-7.

24. Mariani A, Dowdy SC, Podratz KC. New surgical staging of endometrial cancer: 20 years later. Int J Gynaecol Obstet. 2009;105(2):110-1.

25. Thomas SM, Brugge JS. Cellular functions regulated by Src family kinases. Annu Rev Cell Dev Biol. 1997;13:513-609.

26. Yeatman TJ. A renaissance for SRC. Nat Rev Cancer. 2004;4(6):470-80.

27. Sugimura M, Kobayashi K, Sagae S, Nishioka Y, Ishioka S, Terasawa K, et al. Mutation of the SRC gene in endometrial carcinoma. Jpn J Cancer Res. 2000;91(4):395-8.

28. Boucher MJ, Morisset J, Vachon PH, Reed JC, Laine J, Rivard N. MEK/ERK signaling pathway regulates the expression of $\mathrm{BCl}-2, \mathrm{BCl}-\mathrm{X}(\mathrm{L})$, and $\mathrm{MCl}-1$ and promotes survival of human pancreatic cancer cells. J Cell Biochem. 2000;79(3):355-69.

29. Li C, Ahlborn TE, Kraemer FB, Liu J. Oncostatin M-induced growth inhibition and morphological changes of MDA-MB231 breast cancer cells are abolished by blocking the MEK/ERK signaling pathway. Breast Cancer Res Treat. 2001;66(2):111-21.

30. Mitsui H, Takuwa N, Maruyama T, Maekawa H, Hirayama M, Sawatari T, et al. The MEK1-ERK map kinase pathway and the PI 3-kinase-Akt pathway independently mediate anti-apoptotic signals in HepG2 liver cancer cells. Int J Cancer. 2001;92(1):55-62.

31. Kanai M, Konda $Y$, Nakajima $T$, Izumi $Y$, Kanda $N$, Nanakin A, et al. Differentiation-inducing factor-1 (DIF-1) inhibits STAT3 activity involved in gastric cancer cell proliferation via MEK-ERK-dependent pathway. Oncogene. 2003;22(4):548-54.

32. Koochekpour S, Sartor O, Lee TJ, Zieske A, Patten DY, Hiraiwa M, et al. Prosaptide TX14A stimulates growth, migration, and invasion and activates the Raf-MEK-ERK-RSK-Elk-1 signaling pathway in prostate cancer cells. Prostate. 2004;61(2):114-23.

33. Nguyen TT, Tran E, Nguyen TH, Do PT, Huynh TH, Huynh $H$. The role of activated MEK-ERK pathway in quercetin-induced growth inhibition and apoptosis in A549 lung cancer cells. Carcinogenesis. 2004;25(5):647-59.

34. Radziwill G, Erdmann RA, Margelisch U, Moelling K. The Bcr kinase downregulates Ras signaling by phosphorylating AF-6 and binding to its PDZ domain. Mol Cell Biol. 2003;23(13):4663-72.

35. Chen T, Wang C, Liu Q, Meng Q, Sun H, Huo X, et al. Dasatinib reverses the multidrug resistance of breast cancer MCF-7 cells to doxorubicin by downregulating P-gp expression via inhibiting the activation of ERK signaling pathway. Cancer Biol Ther. 2015;16(1):106-14.

36. Wu G, Qin XQ, Guo JJ, Li TY, Chen JH. AKT/ERK activation is associated with gastric cancer cell resistance to paclitaxel. Int J Clin Exp Pathol. 2014;7(4):1449-58

37. Fu X, Feng J, Zeng D, Ding Y, Yu C, Yang B. PAK4 confers cisplatin resistance in gastric cancer cells via PI3K/Akt- and MEK/Erk-dependent pathways. Biosci Rep. 2014;34(2):art:e00094.

38. Wang J, Zhou JY, Wu GS. ERK-dependent MKP-1-mediated cisplatin resistance in human ovarian cancer cells. Cancer Res. 2007;67(24):11933-41.

39. Wu DW, Wu TC, Wu JY, Cheng YW, Chen YC, Lee MC, et al. Phosphorylation of paxillin confers cisplatin resistance in non-small cell lung cancer via activating ERK-mediated Bcl-2 expression. Oncogene. 2014;33(35):4385-95. 